\title{
Assessing the Threat of Incel Violence
}

By Bruce Hoffman, Georgetown University and the Council on Foreign Relations, Washington, D.C.

Jacob Ware, Council on Foreign Relations, Washington, D.C.

Ezra Shapiro, Georgetown University, Washington, D.C.

Contact: jware@cfr.org

\begin{abstract}
In recent years, increasingly serious incidents of violence have been committed by young men predominantly in the United States and Canada who self-identify as incels (involuntary celibates). Although these attacks often specifically target women, the principal source of their animus, men as well as children have been among the casualties in the series of shootings and vehicular homicides that have occurred at universities, high schools, shopping malls, and on city streets. Although, the incel worldview is not obviously political, its core ethos entails the subjugation and repression of a group and its violence is designed to have far-reaching societal effects. Accordingly, incel violence arguably conforms to an emergent trend in terrorism with a more salient hate crime dimension that necessitates greater scrutiny and analysis-especially as it spreads to Europe and shows similarities to and has nascent connections with other terrorist movements.
\end{abstract}


Do fringes of the involuntary celibate (incel) movement pose a terrorist threat? In recent years, attacks linked to extreme fringes of this loosely organized, virtual community have generated increasing concern. Predominantly comprised of young males who congregate on various online forums, incels assail what they believe are the social injustices wrought by genetic determinism and female preferences that have relegated them to the margins of society. Although only a handful of violent incidents have been linked to this movement-including shootings, stabbings, and vehicular rammings - the number of fatalities has climbed to nearly 50 since the first named act of incel violence occurred in 2014.

Yet, the scholarly literature analyzing this phenomenon remains sparse. ${ }^{1}$ Building on the few articles that have appeared in learned journals on this subject along with the variety of journalistic accounts, analyses from think-tanks and other institutions; the work utilizing feminist and gendered interpretations of violence; and, previous research conducted by the authors, ${ }^{2}$ this article describes the movement's ideological contours and the mindset and belief systems of its more extreme adherents; charts the emergence and rise of incel violence; analyzes its targets and the tactics used by the perpetrators; and seeks to provide an assessment of the existing threat and its likely future trajectory.

\section{The Rise of a Movement: The Incels' Online Trajectory}

The involuntary celibate community takes its name from a website created in 1997 by a young female undergraduate at Canada's Carleton University, which she eponymously titled "Alana's Involuntary Celibacy Project." It and other contemporaneous sites aimed to give individuals an outlet for expressing their frustrations over sexuality and dating; but more than 
that, to provide support and rehabilitation for romantically alienated individuals. In "Alana's" own words, "there were a lot of people who were lonely and not really sure how to start dating. They were kind of lacking those social skills and I had a lot of sympathy for that because I had been through the same situation."4 Moreover, such early sites admitted both men and womenan "involuntary celibate" was simply one who had not had sex for some time, despite trying. But as the internet evolved in the early years of the $21^{\text {st }}$ century, it developed its own unique culture, which incel forums consequently began to reflect. Two of the most popular forum platforms, 4chan, founded in 2003, and Reddit, founded in 2005, encouraged extremist declamations in order to gain more visibility. Though incel forums were at this point spread across cyberspace rather than confined to those main platforms, they nonetheless began to espouse similarly edgy and at times extremist sentiment. This in turn created a feedback loop where outrageous statements were intended to generate an escalatory spiral of reactions and responses that disguised their true aggressiveness — a behavior known as trolling or "shitposting." 5

Until less than a decade ago, two different types of incel digital forums appear to have existed: one still emphasized support for those frustrated or unable to find romantic connections, while another was becoming increasingly militant and hostile to women, expressing offensive biologically deterministic memes and openly advocating violence. The former continued to exist on its own website, IncelSupport. But the more extreme elements of this virtual community began to gravitate to another site, LoveShy, founded in 2003. There, the rhetoric and messaging grew increasingly strident, and, as one account of the incel movement recalled, "tilted overwhelmingly male; one of its administrators openly praised mass killers and encouraged another forum member to commit murder." ${ }^{\prime 6}$ Within this less restrained and increasingly more aggressive forum, debates dissected the causes of inceldom - arguing whether looks or 
personality were primarily responsible — and, relatedly whether it was a temporary condition confined to adolescence and perhaps young adulthood, or instead a permanent state of being in which these men were irrevocably imprisoned. Although LoveShy still exists, it gradually lost its attraction for more militant incels after a new, stricter moderator took over and removed the more misogynistic posts. ${ }^{7}$

As new online incel forums proliferated on sites such as 4chan and Reddit, they also became more extreme: either ending or drowning out many of the previous discussions and debates about inceldom. A militant incel identity now began to coalesce with a demonstrably harder edge than before. The difference between the new lamentations and prior ones was the belief that those embracing the label "incel" must act to take control of their lives and exact revenge for the dismissive and derogatory way they were treated. ${ }^{8}$

Reddit became a magnet for militant incels, especially the subreddit r/incels. By 2016, the Reddit incel community had 40,000 users. Then, in 2017, Reddit banned the subreddit for repeatedly violating the website's prohibitions on violent incitement. ${ }^{9}$ A tamer, more heavilymoderated version of $\mathrm{r} /$ incels, called $\mathrm{r} /$ braincels, subsequently surfaced, but it too was banned in September 2019. ${ }^{10}$ At its height, the successor site had attracted only around half the number of users as the original. ${ }^{11}$ Today, incel forums are spread across Reddit and 4chan, have migrated to online community gaming forums like Discord, and also have dedicated websites like incels.co and incels.net. ${ }^{12}$ Although Reddit has reduced the ability to congregate en masse online, extremist threads regularly surface before getting banned. ${ }^{13}$

A multi-national research team studying the incel phenomenon identified four categories of the modern online “manosphere:" "Pick Up Artists (PUAs), Men's Rights Activists (MRAs), Men Going Their Own Way (MGTOW), and Involuntary Celibates (Incels)." ${ }^{14}$ The movements 
all coalesce on similar sites. The authors concluded that "older communities, such as Men's Rights Activists and Pick Up Artists, are becoming less popular and active, while newer communities, like Incels and Men Going Their Own Way, are thriving," while also noting that "worryingly, the latter are more toxic and espouse nihilistic and extreme anti-women ideologies." ${ }^{15}$ As more aggressive newcomers gravitated to these sites and more anodyne expressions of incel frustration grew into violent, online incitement, an ideology began to emerge explaining and justifying the beliefs of the most extreme fringe of this community.

\section{The Black Pill: An Introduction to Incel Ideology and Demographics}

The incel worldview is grounded in two ineluctably intertwined beliefs: their understanding of society as a hierarchy where one's place is determined mostly by physical characteristics, and their identification of women as the primary culprit for this hierarchy. Accordingly, at the top of this structure are the idealized men and women respectively referred to as "Chads" and "Stacys." So-called "normies" are in the middle, with the lowly incels languishing at the bottom. ${ }^{16}$ In incel lore, a small number of Chads attracts the majority of women, leaving only the apparently unattractive women for the normies, and none for incels. ${ }^{17}$ Incels significantly also distinguish themselves from normies not just by their supposedly inferior physical appearance, but by their belief that they have gained privileged insights that normies do not see: that most women are attracted only to Chads, and that if one did not "win" the genetic lottery, they are destined for mediocrity, social isolation, and abject loneliness.

This stratification leads to the second core incel belief: that women are intrinsically shallow and make dating decisions based largely on physical attractiveness, height, weight, and race. Women are thus reflexively drawn to men with the "right" features, the incel ideology maintains, regardless of personality or integrity. And, they are therefore repulsed by men who do 
not conform to this image — even if they are the "supreme gentlemen" described by Elliot Rodger, who perpetrated the first attack claimed in the name of incels. ${ }^{18}$ Incels further believe that because women make judgements about dating based on superficial criteria, they have created an unbalanced, exclusive dating pool, to which incels will never gain access. To the incels' minds, it is women, then, who are responsible for their isolation and rejection—and women are therefore the primary targets of incels anger and violence. ${ }^{19}$

Incels consequently see themselves as destined to be ignored or dismissed by women with no hope or prospects of change. The incels call the epiphany taking the "black pill"-a derivative of the "blue pill/red pill" binary adopted from the 1999 science fiction film, The Matrix ${ }^{20}$ The storyline describes persons taking the blue pill as living in a world of illusion, whereas those who take the red pill undergo an awakening process to the key, fundamental truths about the world. The "manosphere," of which incels consider themselves a part, posits that taking the "red pill" reveals truths about women and society. It empowers those who take it to fully recognize the inherently shallow nature of women, but also to understand better how men can manipulate and exploit these supposed female characteristics. ${ }^{21}$ The black pill, however, is completely nihilistic — taking it means accepting a harsher reality than the red pill reveals, a reality where women and society are intrinsically biased against men who lack specific physical attributes, who therefore have no hope of ever being attractive to women or even accepted by society. "Taking the black pill" is critical to the incel identity, since it means recognizing "inceldom" as a permanent condition. "Black Pillers accept their fate and even dwell in its finality," scholars Jack Bratich and Sarah Banet-Weiser explain. ${ }^{22}$

Online surveys of incels provide a partial, entirely self-reported window of this digital community's core. According to a March 2020 survey of incels.co forum users, they are 
predominantly young males, many of whom live with their parents and have never been intimate with or had any kind of a meaningful relationship with a woman. ${ }^{23}$ North Americans and Europeans made up over 80 percent of respondents. Most were Caucasian. Half never attended college, despite hailing from mostly middle and upper class socio-economic backgrounds. Incels also display indications of mental illness or profound trauma and distress. Almost 70 percent of respondents claimed to suffer from depression, while over a quarter self-identified as autistic. Notably, these results dovetail with scholarly research on lone-wolf terrorism, which similarly reveal higher rates of mental illness than other violent actors. ${ }^{24}$

\section{Typology and Political Violence}

Admittedly, the incel worldview is not obviously political. But because its core ethos revolves around the subjugation and repression of a group and its violence is designed to have far-reaching societal effects, incel violence arguably conforms to an emergent trend in terrorism with a more salient hate crime dimension. As a January 2020 Texas law enforcement assessment notes, "what begins as a personal grievance due to perceived rejection by women may morph into allegiance to, and attempts to further, an Incel Rebellion." ${ }^{25}$ According to a team of scholars who analyzed the violent incel mindset within a specific terrorism context, ingroups and outgroups are not understood as isolated entities but as parties in a large story/plot that unites their respective fate in way of the outgroups oppressing the ingroup until the ingroup is restored to the initially better position thanks to a radical overthrow ... the Incel worldview rests on a clear, overarching narrative linking the ingroup with its outgroups in a chronological succession of events that gradually aggravated the situation of the ingroup up to an extreme point. ${ }^{26}$ 
Accordingly, the extreme fringes of the incel community, as well as the violence they have committed, should be considered terrorism.

\section{Understanding the Dimensions of Incel Violence}

To date, violence committed by males calling themselves incels or in sympathy with incel ideology has claimed the lives of nearly 50 victims. Although the half dozen or so incidents that account for this death toll reveal little-to-no coordination among the perpetrators, the homicidal intent that underpins this movement is undeniable, averaging almost eight fatalities per incident. But, despite the six years that have passed since the first incel attack occurred, and the extensive media coverage that has followed, the dynamics and pattern of incel violence and ideology remain poorly understood.

To better assess and distinguish between the succession of violent incidents categorized as incel attacks, we consider incel violence as fitting into one of four categories:

- Clear incel-motivated terrorist attacks;

- Attacks with mixed motives that evidence incel ideological influences;

- Acts of targeted violence perpetrated by self-professed involuntary celibates; and,

- Ex post-facto inceldom

Clear incel-motivated terrorist attacks: The most important category for this article, these are acts of political violence with explicit political and ideological aims committed by males claiming to be part of the incel community via its online presence. In all these cases, the perpetrators publicly expressed their motivation and were primarily driven by their inceldomthat is, their declared affiliation with, and adherence to, the incel movement. To date, there have been three clear incel-motivated terrorist attacks. 
The first recognized incident of incel violence occurred in May 2014, when 22-year-old Elliot Rodger attempted to attack a sorority house at the University of California, Santa Barbara. After failing to gain entry, he targeted random passersby on the streets of Isla Vista, California. Rodger left behind a 133-page manifesto, titled My Twisted Life. "All I have ever wanted was to love women," he complained,

but their behavior has only earned my hatred. I want to have sex with them, and make them feel good, but they would be disgusted at the prospect. They have no sexual attraction towards me. It is such an injustice, and I vehemently questioned why things had to be this way. Why do women behave like vicious, stupid, cruel animals who take delight in my suffering and starvation? Why do they have a perverted sexual attraction for the most brutish of men instead of gentlemen of intelligence? I concluded that women are flawed. There is something mentally wrong with the way their brains are wired, as if they haven't evolved from animal-like thinking. They are incapable of reason or thinking rationally. They are like animals, completely controlled by their primal, depraved emotions and impulses. That is why they are attracted to barbaric, wild, beast-like men. They are beasts themselves. Beasts should not be able to have any rights in a civilized society. If their wickedness is not contained, the whole of humanity will be held back from advancement to a more civilized state. Women should not have the right to choose who to mate with. That choice should be made for them by civilized men of intelligence. ${ }^{27}$

Rodger also posted numerous misogynistic videos on YouTube, outlining his profound sense of alienation because of this serial rejection and his concomitant hatred of women. In the 
end, however, only two of Rodger's six victims were women. Rather than surrender to police, he then killed himself. As the first self-identified, violent incel, Rodger has since come to be regarded by the movement's adherents as its "patron saint" — an ideological touchstone and inspiration. Extremist incels, for instance, routinely encourage each other to "go ER;" that is, to follow Rodger's murderous precedent by engaging in similar acts of terrorism before taking their own lives. ${ }^{28}$

The deadliest incel terrorist attack inspired by Rodger's example occurred in April 2018 in Toronto, Canada. A 25-year-old male named Alek Minassian drove a rented van through one of the city's busiest streets, striking pedestrians and ultimately killing 10 persons, eight of whom were women. Investigators identified Minassian's motive after finding a social media post in which he declared "Private (Recruit) Minassian Infantry 00010, wishing to speak to Sgt 4chan please. C23249161. The Incel Rebellion has already begun! We will overthrow all the Chads and Stacys! All hail the Supreme Gentleman Elliot Rodger!" ${ }^{29}$ Minassian surrendered to police and is currently awaiting trial. ${ }^{30}$

The third unambiguous incel terrorist incident occurred in November 2018, when two women were killed by 40-year-old Scott Beierle at Tallahassee Hot Yoga studio in Tallahassee, Florida. Beierle then committed suicide. He was a long-time adherent to involuntary celibate ideologies, and posted videos on YouTube and music on Soundcloud outlining his misogynistic views and expressing support for his incel predecessors. ${ }^{31}$

The most important distinguishing feature of this category is the specific targeting of ideologically symbolic locales, that is ones populated largely by women: the main source of the incel movement's animus. Rodger targeted a sorority house after stabbing his three male roommates to death. Minassian claimed his violence was directed predominantly against 
"Chads," although, as noted above, the overwhelming majority of his victims were female. And Beierle specifically selected a hot yoga studio where he was certain there would be women, shooting six of them. The one man in the yoga studio that evening, who in fact rushed Beierle, was pistol-whipped, but not shot. ${ }^{32}$ Beierle could arguably have murdered this man, but clearly chose not to.

This category also reveals the learning curve apparent among incel terrorists. After Rodger's attempted shooting rampage at the Alpha Phi sorority house, he proceeded to drive through the streets of Isla Vista, striking pedestrians between random gunshots. Not only did Minassian cite Rodger as his inspiration; he also followed his lead with his own car ramming attack along one of Toronto's main thoroughfares. Beierle, meanwhile, emulated Rodger's example in selecting a target where women typically were present—which would therefore leave no doubt about his motivation.

Attacks with mixed motives that evidence incel ideological influences: This category embraces attackers who espouse or identify with incel ideology and hence may frame their violence within that context. The distinguishing factor of these incidents, however, is that they are not obviously perpetrated expressly for political purposes or in furtherance of the incel agenda. Rather, the perpetrator simply refers to or mentions their incel ideology in the lead up to the attack.

Of the three violent attacks in this category, the first occurred in October 2015, when Christopher Harper-Mercer opened fire at the Umpqua Community College in Roseburg, Oregon, killing nine persons; the second in December 2017, when William Atchison murdered two students at Aztec High School in Aztec, New Mexico; and the third in February 2018, with a mass shooting at the Marjory Stoneman Douglas High School in Parkland, Florida, carried out 
by Nikolas Cruz, where 17 persons were killed and 17 others were wounded. Excluded from this count is a failed attack in June 2019, in which Brian Isaack Clyde was shot dead by police after opening fire at the Earle Cabell Federal Building and Courthouse in Dallas, Texas—an apparently successful instance of "suicide-by-cop."”33

Each of the perpetrators had previously referenced some aspect of inceldom in prior online or offline postings. Harper-Mercer wrote that "my whole life has been one lonely enterprise. One loss after another. And here I am, 26, with no friends, no job, no girlfriend, a virgin. I long ago realized that society likes to deny people like me these things. ${ }^{{ }^{34}} \mathrm{He}$ also described Elliot Rodger as "[standing] with the gods." Atchison meanwhile had used "Elliot Rodger" as his online pseudonym, and, like Minassian, had praised Rodger as a "supreme gentleman. ${ }^{35}$ Cruz had similarly complained about social isolation; and, although he seemingly did not actually self-identify as an incel, he did post a comment online before his assault, declaring that "Elliot Rodger will not be forgotten." ${ }^{36}$ Perhaps notably, the school shooting occurred on Valentine's Day.

Harper-Mercer, Atchison, and Cruz all outwardly expressed a fascination with incel ideology and an admiration for Elliot Rodger, but their attacks were less clearly, and perhaps not directly, motivated by incel ideology. Significantly, too, the violent incidents in this category did not appear to target women. Instead, they targeted schools, perhaps further indicating the absence of a specifically political motive. Accordingly, each fits the "aggrieved entitlement" model presented in a 2010 issue of Health Sociology Review, a scholarly journal, which explained how "school shootings may be thought of as an appropriate, instrumental way for young adolescent . . . while preserving, if not actually enhancing, their perception of their own masculinity through 
the aggrieved entitlement of their violence." ${ }^{37}$ These school shootings have particularly proven deadly—averaging over nine deaths per attack. ${ }^{38}$

Acts of targeted violence perpetrated by self-professed involuntary celibates: In this category, we include targeted acts of violence—including murders and assaults—perpetrated by persons who may refer to themselves as incels or are apparently cognizant of the incel ideology but not otherwise firmly situated within it. Similar instances where the perpetrator blames their acts of violence on sexual frustration and loneliness are also included here. Significantly, this violence is neither indiscriminate nor focused on public gatherings or crowds but is directed against individual persons.

Three incidents can be highlighted as examples, although there are arguably many others. In July 2016, Sheldon Bentley, a Canadian security guard, stomped a man to death in Edmonton, Alberta. Bentley cited sexual frustration and inability to find a partner as the reasons behind the attack. ${ }^{39}$ He made no specific mention of inceldom or incel ideology. In April 2019, Emmanuel Aranda threw a young boy off a third-floor balcony at the Mall of America in Bloomington, Minnesota ${ }^{40}$ Aranda explained that "he had been coming to the Mall for several years and had made efforts to talk to women in the Mall, but had been rejected, and the rejection caused him to lash out and be aggressive." ${ }^{41}$ And, last June, a 26-year-old named Alex Stavropoulus stabbed a mother in the neck at a Sudbury, Ontario shopping center. Stavropoulus claimed he wanted to harm the woman's young daughter. "I like white women, but they won't $f^{* * *}$ me," Stavropoulus explained to arresting police officers. "So I wanted to see what it felt like (to kill a female child). [...] I had my mind set. I was going to kill a child and was waiting for the right opportunity." ${ }^{\prime 2}$ This category thus includes targeted assaults or attacks which are primarily caused by sexual frustrations but do not clearly aim to advance a political or ideological message. To be 
clear, these are not clear incidents of political terrorism, or even hate crimes. The assailants are not necessarily self-declared members of the incel community. But their violent acts evidence the role that misogyny and sexual frustration can play in sparking violence, even when the target is seemingly random. For that reason, they are the category that solicit arguably the most adamant concern amongst feminist scholars. ${ }^{43}$

Ex post-facto inceldom: In addition to the above, it is important to note an entirely different category whereby the incel community retroactively inducts past attackers, even predating Elliot Rodger, into a virtual pantheon of incel heroes. While many of these males could not have been part of online incel communities, as their actions predate the advent of most online forums, their violent acts nonetheless conform to the patterns of social isolation generally, and rejection by women specifically, that animated subsequent incel violence. Incels have taken these historical incidents of misogynist mass violence as proof that involuntary celibacy has precipitated violence in the past, and that such men should therefore be lauded for their actions. Marc Lépine, a Quebecois antifeminist who murdered 14 women at the École Polytechnique de Montréal in December 1989, ${ }^{44}$ and George Sodini, who killed three women in an August 2009 shooting at the LA Fitness health club in Collier Township, Pennsylvania, are particularly immortalized in incel lore. ${ }^{45}$ Perpetrators of school shootings at Columbine High School in Colorado; Virginia Tech in Blacksburg, Virginia; and Sandy Hook Elementary School in Newtown, Connecticut, among others, have also all been posthumously honored to various degrees by incels. ${ }^{46}$

\section{Incels and the Far-Right}

A particularly worrisome trend is how seamlessly the militant incel community has been integrated into the alt-right tapestry, with common grievances and intermingling membership 
bringing the two extremisms closer together. ${ }^{47}$ As a 2019 report from the Center for Analysis of the Radical Right observed, the incel masses "are part of a growing trend of radical-right movements that are anguished by the success of neoliberalism," particularly women's empowerment and immigration. ${ }^{48}$ The Anti-Defamation League of B'nai B'rith has also noted the links between "men's rights activism" and the neo-fascist militant Proud Boys, further reinforcing the convergence of politicized misogyny with far-right activism. ${ }^{49}$

Whether or not they are specifically intrinsic to incel ideology, racial themes are functionally inextricable from the incel narrative. Elliot Rodger's manifesto, for instance, was a thoroughly racist document. At one point, Rodger bemoans an African-American friend's sexual experiences, saying "how could an inferior, ugly black boy be able to get a white girl and not me? I am beautiful, and I am half white myself. I am descended from British aristocracy. He is descended from slaves. ${ }^{{ }^{50}}$ Similar racist discourse with no direct connection to incel ideology also appears prominently on forums, where Indian and East Asian incels are respectively referred to as "currycel" and "ricecel." 51 The white supremacist discourse pervasive on incel forums is particularly ironic given the racial makeup of incel perpetrators to date. Of the six attackers previously mentioned in the top two categories, four-Rodger, Harper-Mercer, Minassian, and Cruz - were either multiracial or do not conform to the white, Anglo-Saxon ideal of the violent, far right.

Many incels also rail against Jews. Though not necessarily part and parcel of the cultural narrative, the classic anti-Semitic refrain about Jews controlling society — through government, banks, and the media - is relatively common among incels in identifying the causes of social decay and degeneration. ${ }^{52}$ In fact, several of the perpetrators also professed vehemently antiSemitic views. Scott Beierle, for instance, was called "Nazi Scott" by an old social group; ${ }^{53}$ 
Nikolas Cruz had carved swastikas into gun magazines used on the day of his massacre; ${ }^{54}$ and William Atchison posted on Steam that "I hate the "ing jews. I always have, I always will." 55 Analyses and reports published by the Anti-Defamation League, which actively tracks incel violence, also typically provoke anti-Semitic online postings and abuse on incel forums. ${ }^{56}$ Incels, like their extreme far-right brethren, also despise feminism, arguing that more progressive policies towards gender equality are the root of many of the globe's problems. Part of this anger is the product of individual loneliness; the other, more ideological factor is their argument that society has become an oppressive matriarchy. Incels describe their ideal world as traditional and family oriented. Reactionary views permeate incel discourse, and though this is not inherently a far-right worldview, a common refrain in forums yearns for the "old days," when men had more control over women, monogamy was the norm, and it was allegedly easier to find a spouse. Feminism, they say, has robbed incels of the right to a wife and sex — which some incels seek to redress through violence. In fact, some incels argue that the denial of sex constitutes a "reverse rape" - and that such offenses are as harmful as real rapes. ${ }^{57}$

Far-right online communities have noticed the incel rhetoric's racial and men's rights undertones and thereby sought to deepen ties between these movements. Incels and far-right adherents now regularly, openly intermingle on sites like Reddit and 8kun. Alek Minassian, for instance, posted a pre-attack message on an alt-right 4 chan image board. ${ }^{58}$ Opposition to feminism, the most fundamental shared belief between these two extremisms, is often described as the "gateway" to more recognized far-right ideology. ${ }^{59}$ Indeed, the online "manosphere" and related men's rights activism has become a breeding ground for racist, anti-Semitic, and antiLGBT views. As Ashley Mattheis of the Centre for Analysis of the Radical Right, argues, "once you engage with the idea that a social-justice-warrior club and the feminist movement have 
increased the precarity of men, that moves over time into the increased precarity and endangerment of 'the West," - a seminal far-right grievance. ${ }^{60}$

To illustrate the point, several recent European far-right attackers have displayed incel tendencies, whether in public statements or in their online profiles. The 18-year-old perpetrator of a July 2016 mass shooting in Munich, Germany, had been in close contact with William Atchison, the Aztec High School shooter, who would write an obituary for his friend after the former's attack. ${ }^{61}$ The gunman who targeted a mosque in Bærum, Norway in August 2019 referenced incel memes prior to his largely failed attack. ${ }^{62}$ The perpetrator of an October 2019 shooting at a synagogue and kebab shop in Halle, Germany, confessed to his crimes by claiming that immigrants had stopped him getting a girlfriend. ${ }^{63} \mathrm{He}$ also described himself as a "loser" and a "disgruntled white man," ${ }^{64}$ and cited feminism as "the cause of declining birth rates in the West" in his livestream - all typical themes in the incel mindset and ideology. And the 43-yearold far-right terrorist who murdered nine in shootings at two shisha bars in Hanau, Germany, in February 2020, released a lengthy manifesto in which he explained he had never had a relationship with a woman. ${ }^{65}$ Several European far-right terrorists' repetition of common incel refrains, while not necessarily indicative of their own membership in the community, point to an increasing convergence between the radical right and incel communities, particularly online, as well as the enduring role that sexual frustration and loneliness can play in sparking political violence.

Finally, incel violence shares a similarity with far-right terrorism in that these violent acts are disproportionately committed by former members of the military. ${ }^{66} \mathrm{Of}$ the six perpetrators who committed either a clear incel-motivated terrorist attack or an attack with mixed motives that evidenced incel ideological influences, four had some degree of military training: Minassian 
was a former recruit with the Canadian Armed Forces who was discharged after only 16 days, ${ }^{67}$ while Beierle had been a second lieutenant in the U.S. Army before being kicked out for "unacceptable conduct," ${ }^{68}$ Harper-Mercer had enrolled in the U.S. Army before failing basic training, ${ }^{69}$ and Cruz was a star Junior Reserve Officers' Training Corps pupil. ${ }^{70}$ Brian Isaack Clyde, meanwhile, was a former infantryman in the U.S. Army. ${ }^{71}$ This reflects a trend among violent, far right extremist groups. They deliberately recruit from various militaries, and several recent violent incidents — including the August 2012 Sikh temple shooting in Wisconsin, the stabbing of a black man in New York City in March 2017, and the Halle synagogue shootingwere perpetrated by military veterans. Though most of the perpetrators had short and checkered military careers, they may nonetheless have made use of the skills imparted during training and exercises to enhance the lethality of their attacks.

\section{Learning from Jihadists?}

Beyond the far-right, the more violent manifestations of the incel community share some similarities with their more deadly Islamic State counterpart. Firstly, like the modern Islamist extremists, incels congregate online, seeking out increasingly private and better-encrypted sites on which to share and discuss their radical views. The online space exacerbates the incel threat by accelerating two, mutually reinforcing trends: online entrenchment both intensifies one's grievances as well as pushes one further towards violence. In the words of Graeme Wood, who is among those who has intensively studied and reported on the Islamic State, "dating is harder when you spend a lot of time being bitter online. Murder is easier when someone is whispering at you every few minutes, telling you the rest of the world deserves what it gets." 72 This has proven true in the incel case: as Alek Minassian said of Elliot Rodger, "other members of 4chan were giving him encouraging support so that he would have the courage to start his rebellion."73 
Perpetrators of incel violence are often widely praised in forums after these violent incidents and heralded as "saints" and "heroes." On other occasions, particularly when planned assaults have not gone according to plan, these failures are ridiculed for their low death tollsthe last straw in an apparently pathetic incel's miserable life. For instance, in one incels.co thread commemorating the one-year anniversary of the attack committed by "St. Yogacel"-Scott Beierle - in Tallahassee, commenters varied in their responses to the murders. One poster praised Beierle, celebrating "a true gentleman and hero;" another mocked him, complaining that "the guy was in the military and only got 2 kills $[\ldots]$ i thought his trainin would make him plan to be as deadly as possible." 74

Mobilizing online entreaties several advantages to extremist groups: most notably, it makes incels more accessible to curious minds across the globe, who now only need an internet connection to be radicalized. In Alek Minassian's own words, "it makes it very easy and you can hide behind a computer screen." 75 This also makes them harder for counterterrorist forces to tackle, particularly in the United States, where any proposal to restrain radical posts sparks a First Amendment debate. By establishing ideologically cohesive echo chambers, social media unites disparate individuals separated by background and geography and offers a networked universe and common purpose. ${ }^{76}$ And then, every once in a while, as the Islamic State and incels have both displayed to devastating effect, somebody breaks away from these virtual domains to commit real world violence. ${ }^{77}$

Secondly, like jihadists, violent incels have developed a culture of martyrdom, in which past murderers are venerated as heroes to admiring future generations. The community's most important martyr, Elliot Rodger, is hailed as a hero on incel forums - his description of himself as a "supreme gentleman" has become an oft-repeated mantra among incels, as Alek Minassian's 
Facebook post attests. Through his dramatic act of violence and subsequent suicide, Rodger deliberately sought not only to terrorize women, but to inspire a broader uprising of men to follow in his footsteps. Minassian has also become a venerated figure - in the wake of his attack, one forum commenter celebrated "that moment when this random dude killed more people than the supreme gentleman Elliot. I hope this guy wrote a manifesto because he could be our next new saint."78

Five of the seven men in the top two categories of incel violence died of gunshot wounds, four self-inflicted. One of the two who survived their attack, Canadian Alek Minassian, is also the only incel perpetrator who did not use a firearm and also admitted in police interviews that he had planned his attack in such a way that he hoped he would be killed by police. ${ }^{79}$ In the jihadist context, suicide terrorism is proven to inspire continued violence and ensure the assailant's standing among their surviving constituency. ${ }^{80}$ Incels are now following that lead.

Thirdly, and related to both movements' online mobilization, there may be similarities in the radicalization processes and factors which animate individuals to turn to extremism. Sex and sexuality, for example, is a powerful mobilizer for young men, and its role in radicalizing Islamic State members has been documented. ${ }^{81}$ Indeed, British academic Simon Cottee made exactly this case in the wake of the Toronto van incident: "It is not difficult to spot parallels with the world of jihadism, where women and sex are similarly fixated on to an extraordinary degree." 82 Similarly, sociologist Mark Juergensmeyer has noted in the context of religious violence that "Nothing is more intimate than sexuality, and no greater humiliation can be experienced than failure over what one perceives to be one's sexual role. [...] Terrorist acts, then, can be forms of symbolic empowerment for men whose traditional sexual roles - their very manhood — is perceived to be at stake." 83 The same could easily be said for incel terrorists. 
Finally, incels have also displayed a willingness to adopt Islamic State tactics. Minassian was perhaps influenced by jihadist successes with vehicular attacks and hence chose to drive a rented van down Yonge Street in Toronto, striking bystanders. In applying a tried and tested tactic, Minassian succeeded in committing the deadliest clear incel incident to date. As Wood has argued in the context of Islamic State violence, "Sexually undesirable losers have long taken out their frustration on others - mostly individual women; but now, after $[\ldots]$ years of Islamic State R\&D, the menu of mayhem is greatly expanded." ${ }^{84}$ Suicide terrorism is also a tactical innovation popularized by jihadists. Suicide attacks tend to be deadlier, because the perpetrators do not need to plan the most difficult element of an operation: how to get away. ${ }^{85}$

\section{Counterterrorism Challenges and Opportunities}

The central question for this analysis is also the most important for law enforcement to answer: is the threat from violent incels increasing, or has the movement plateaued? To be sure, more violently-inclined incels have remained emboldened, and there is ample reason to believe violent incels remain a grave terrorism threat. This is reflected in recent law enforcement warnings about the community. In September 2019, the U.S. Army, for instance, warned its servicemembers about potential violence at screenings of the Joker movie, after picking up "disturbing and very specific chatter" on incel chats on the dark web. ${ }^{86}$ And, the previously cited January 2020 Texas Department of Public Safety domestic terrorism threat assessment talked at length about incels, warning that "the violence demonstrated by Incels in the past decade, coupled with extremely violent online rhetoric, suggests this particular threat could soon match, or potentially eclipse, the level of lethalness demonstrated by other domestic terrorism types." ${ }^{\prime 7}$

The political prioritization of counterterrorism efforts against Salafi-jihadist extremism also complicates domestic efforts against incels: it is more constitutionally challenging, and 
arguably less politically expedient, to take on legal extremism emerging from one's own domestic constituents than those allegedly originating abroad. Furthermore, like radicals on the far-right and far-left, incels do not conform to the traditional model of terrorism. Because of the power of the Internet, social media, and other 21 st century communications platforms, terrorism is increasingly becoming a solitary venture, primarily perpetrated by lone actors operating outside formal organizations. Accordingly, violent incels challenge counterterrorism policies and strategies which have long been oriented towards targeting terrorist groups and their leaders. ${ }^{88}$

That said, it is worth considering the possibility that incels might conspiratorially plan and coordinate attacks together. Alek Minassian, perpetrator of the Toronto van incident, claimed in a police interview conducted after his arrest that he had been in direct communication with both Elliot Rodger and Christopher Harper-Mercer. Together, they had, in Minassian's telling, been "plotting certain timed strikes on society in order to confuse and shake the foundations, just to put all the normies in a state of panic." ${ }^{89}$ One cannot verify his claim, but needless to say, more cohesive and organized incel plotting would intensify the terrorist threat.

Finally, counterterrorism efforts are complicated because, like extremist far-right and Islamist communities, incels are increasingly turning to the dark web to congregate, debate, and radicalize new followers. Incels are clearly aware of - and moreover often bask in - the attention they receive from mainstream media and law enforcement. This has led to both top-down and individual self-censorship in order to avoid incel forums being shut down, as happened to Reddit's popular/r/incels in November 2017. Today, for instance, violent posts on visible forums are often met with wry comments about possible law enforcement oversight. In November 2019, for example, one forum interlocutor responded to a thread comment claiming "going ER as a lone wolf seems cooler tbh [to be honest]" with the simple, sarcastic warning: "hello FBI."90 
This censorship has doubtless caused more violent incels to migrate to more discrete forums such as abstruse gamer chatrooms and the dark web. In another parallel to the violent, extreme right, this includes sites like Gab, an openly far-right social media site. ${ }^{91}$

There are also counterterrorism opportunities. The incel community is hardly monolithic or unified, thus opening myriad opportunities for intervention. Because the community displays high levels of variability, it therefore lacks the cohesiveness prevalent in other violent radical movements. In other words, while incels agree on a description of the problem-biological determinism and a society in which females wield too much power-they disagree on the prescription. Is it to "facemaxx/gymaxx" and therefore try to reinvent themselves; give in to their lonely fate and "lay-down-and-rot" as the incel argot claims; to "go ER" and become violent; or is it perhaps to plot some grander societal makeover to be achieved through violence and intimidation? Some see violence as essential to achieving an incel end goal, whether that be policies to ensure sex for all men or an end to feminism; some simply see it "as a gratuitous, liberating act of revenge without any hope of gaining something." ${ }^{, 92}$ Given that there are, at a minimum, many thousands active on incel forums coupled with the inherently fractious nature of these platforms, it is unsurprising that the community disagrees about self-definition and teleological issues.

In addition, incels pride themselves on their so-called "shitposting," which makes it challenging to ascertain — and easy to overestimate — the dimensions of the actual threat. The online community, of which incels are a subset, has a culture layered in sarcasm and satire; this veil is challenging for a dilettante to penetrate, and makes it difficult to parse incel ideology and assess actual radicalization as a prelude to violence. A premium is put on saying outrageous, edgy things since these posts get the most attention and provoke the most discussion. Moreover, 
many incels say these forums are their only space to vent and share their darkest thoughts, because they have no other outlet to be heard. This often makes it difficult to tell which posts may constitute a threat, and which are just cathartic satire or false bravado. While this does mean that not all incel rhetoric should be believed or even given attention, ultimately, it may not matter: "Shitposting" can nonetheless confirm the violence-prone beliefs of a few individuals and thus contribute to radicalization and ultimately mobilization.

\section{Policy Recommendations for Countering Incel Violent Extremism}

Given the ongoing threat of extremist incel violence, focused efforts are needed to counter their extremist worldview and increasingly aggressive ideology. These include improved countering violent extremism (CVE) programming, better monitoring and management of extremist communities online, continued improvement in our strategies to tackle lone actor terrorism, and more widespread access to mental health resources for young men online.

Any successful strategy to counter the potentiality of increased incel terrorism will require devoting more energy and resources to community initiatives designed to counter violent extremism (CVE). The incel movement is particularly dangerous because of its accessibility: incel radicalization takes genuine pain and searing loneliness and converts it into hatred, anger, and violence. Learning how to better intercept incel radicalization while the individuals are still in the pain and loneliness stage is an urgent imperative. "Alana," whose online forums in 1997 introduced the involuntary celibate concept, recently founded Love Not Anger, an organization dedicated to pushing back against incel hatred by addressing the abject loneliness evident across these online forums. ${ }^{93}$ Moonshot CVE, a countering violent extremism enterprise, is also intensifying its efforts, noting that "the incel ecosystem thrives - even depends - on the social isolation of its online spaces. It is therefore critical, both for its members and for public safety, 
that we work together to bridge the online-offline gap by getting incels the help and support they so desperately and self-evidently need." 94 Supporting, encouraging, and replicating these and other such initiatives will be central to any effective countermeasures. There is nothing inherently wrong with a community of young people who have trouble finding love and relationships forming online support groups. But the ongoing vilification of a targeted outgroup with extreme rhetoric and violent suppression presents a grave danger - it harnesses real sadness and frustration, turns it into hatred, and focuses it in harmful directions. The best way to prevent incel terrorism, accordingly, is to undermine incel ideology in the first place through rehabilitation and insulation from new extremist blandishment.

Both governments and the technology companies who provide these digital platforms must also collaborate more and better to counter the spread of online violent extremist ideologies. Although specific incel forums themselves are relatively well self-policed, posts on more eclectic sites, including 4chan and 8kun, continue to call for violence against women and minorities as well as provide a location where extremist manifestos can be posted in advance of violent acts. Recent international efforts to counter online extremism include the April 2019 UK government's “Online Harms” White Paper, meant to more effectively tackle threatening online content. "If we surrender our online spaces to those who spread hate, abuse, fear and vitriolic content, then we will all lose," it argued, before presenting "ambitious plans for a new system of accountability and oversight for tech companies, moving far beyond self-regulation." 95 And in June 2019, in the wake of a devastating far-right attack on two mosques in Christchurch, New Zealand Prime Minister Jessica Ardern instigated the Christchurch Call, an international political summit to address online extremism and the role of social media companies in its propagation. The ensuing document, which issues a promise to "counter the drivers of terrorism and violent 
extremism by strengthening the resilience and inclusiveness of our societies to enable them to resist terrorist and violent extremist ideologies, including through education, building media literacy to help counter distorted terrorist and violent extremist narratives, and the fight against inequality," has been signed by upwards of 50 countries. ${ }^{96}$

In the U.S., stringent free speech laws make passing legislation to tackle online extremism more difficult, but alternative measures to undermine the free reign of extremist movements over online spaces have been suggested by journalists, scholars, CVE practitioners, and politicians alike. ${ }^{97}$ For now, a broader conversation is needed on how to push back against extremism and violent ideologies online, involving tech companies, terrorism and radicalization experts, governments, and even former extremists and young social media users. As the authors of the aforementioned article that appeared in Terrorism and Political Violence argue, "the role of the Internet in enabling the formation and radicalization of this community through echochamber dynamics is evident: without a way to relate and discuss, these individuals would have had no way to recognize themselves as 'Incels' and learn the culture and particular idioms that cements the Incel worldview." ${ }^{98}$ More effectively addressing the role of the internet in empowering incel mobilization is therefore a critical priority. Challenging the incels' online sanctuary would concurrently degrade far-right ideologies and their spread online as well.

There is also a concomitant need to improve how we address the rising threat of lone actor terrorism, which is rising ${ }^{99}$ Lone actors often emerge from online networks, which pride themselves on the proliferation of violent and radical rhetoric, and where would-be and actual terrorists are known to talk to each other, but the final acts themselves, in almost all recent cases, have been planned, financed, practiced, and executed by violent extremists acting entirely on their own. This has indeed been the case with the violence cited in this article, despite 
Minassian's claim that he spoke and coordinated with Elliot Rodger and Christopher HarperMercer. With respect to incels, as well as other primarily lone actor threats, an essential foundation is building more knowledge about radicalization and recruitment practices, especially as they have evolved and proliferated in an era of social media and digital communication. Better understanding these processes can reveal likely indicators to facilitate intervention, pre-emption, and prevention of such attacks.

Most of the most revelatory published research on incels, however, has been conducted by journalists and not scholars, much less law enforcement officers and intelligence analysts. This may explain why gender-based terrorism and gendered narratives within extremist movements more broadly have been better covered within feminist scholarship. Long before the advent of incel violence, for instance, scholars such as Laura Sjoberg, Cynthia Cockburn, and Michael Kimmel highlighted the role that male sexual frustrations can play in political and public violence. ${ }^{100}$ Sjoberg, a pioneer of the feminist theory of war, has argued that gender is essential to any study of war and violence. ${ }^{101}$ Kimmel's work on what he terms "aggrieved entitlement" sheds further light on the role that a male sense of victimization can play in sparking extremism and eventually violence. ${ }^{102}$ And Cynthia Miller-Idriss, Hilary Pilkington, and Ashley Mattheis have highlighted how gendered societal views both facilitate radicalization and influence the ideology and mindset of the alt-right. ${ }^{103}$

Feminist scholarship has also pioneered the analysis of the so-called manosphere. Debbie Ging's article, "Alphas, Betas, and Incels," is among the most important contributions to this field, expertly detailing how the incel movement grew out of rapid revolutions in online communication and social organizing. ${ }^{104}$ Work by Maria Scaptura and Kaitlin Boyle has examined the role that violent fantasies and perceived challenges to one's masculinity can play in 
inspiring incel violence, ${ }^{105}$ while Marwick and Caplan highlight the manosphere's attitude towards feminism, and the tools and tactics it uses to harass women online. ${ }^{106}$ Alex DiBranco established the Institute for Research on Male Supremacism, which aims to provide critical research on emerging men's rights extremist groups—including incels. ${ }^{107}$ And, finally, Kate Manne's Down Girl: The Logic of Misogyny, begins with an incisive analysis of incel violence. ${ }^{108}$ The feminist academy, clearly, has led the charge in analyzing the environment in which incels operate and the root causes of their violence. Their contributions are essential to our understanding of the movement and the terrorism it can inspire — and have established a firm foundation from which research on incels can benefit.

Finally, and perhaps most importantly, we must dramatically improve access to mental health resources for young men online, while continuing to break down stigmas inhibiting such intervention. ${ }^{109}$ Illnesses such as depression and anxiety run deep in the incel community, according to surveys of persons populating these online sites. These mental health issues also surface in the suicidal rhetoric expressed on these forums. Mitigating this proclivity to despair and suicide could blunt or obviate what could become a self-fulfilling pathway to violence. With the exception of Nikolas Cruz's Parkland rampage, every other incel-inspired or -related attack has been a successful or attempted murder-suicide. Arguably, the most effective way to prevent an incel from "going ER" is by proactively addressing his suicidal impulses.

Providing better mental health access and counseling for these young men would likely also impact the disturbing trend towards non-ideological mass violence, such as school shootings. As the aforementioned article published in the Health Sociology Review argues, school shootings in the United States are often triggered by what the authors term masculine 
"aggrieved entitlement" - whether they ultimately have an ideological veneer or not. "Aggrieved entitlement inspires revenge against those who have wronged you," the article explains;

it is the compensation for humiliation. Humiliation is emasculation: humiliate someone and you take away his manhood. For many men, humiliation must be avenged, or you cease to be a man. Aggrieved entitlement is a gendered emotion, a fusion of that humiliating loss of manhood and the moral obligation and entitlement to get it back. ${ }^{110}$

"Aggrieved entitlement" has been a central factor in mass shootings before and since the birth of the incel movement. Teaching young men to deal with it could also potentially avert the violent inclinations of incels.

All of these counterterrorism recommendations are in fact cross-ideological—in other words, they would not just degrade violent incels, but other terrorists as well. CVE best practices learned from tackling incels, for example, could be applied to their violent far-right counterparts. More effective management of social media and suppression of radical ideology and rhetoric online would damage every extremist movement—as would improved online access to mental health resources. And better defenses against lone actor terrorism would more reliably keep Americans safe from any terrorist threat. The extreme fringe of the incel movement is in many ways very similar to its violent far-right and Islamist counterparts—-for example, all three largely mobilize online, target personal insecurities and vulnerabilities in their radicalization strategies, and seek to inspire lone actors to attack. More effectively pushing back against one threat would likely help address all three.

\section{Conclusion:}


The concern many hold over incels and the threat they may pose was aptly captured by Zack Beauchamp, a journalist who has extensively covered the movement: "Only a tiny percentage of incels seem willing to turn to violence or terrorism," Beauchamp argues, "and the movement isn't a threat on the level of an al-Qaeda or ISIS. But it's a new kind of danger, a testament to the power of online communities to radicalize frustrated young men based on their most personal and painful grievances." 111 Increased counterterrorism focus on the violent fringes of the incel movement should not necessarily mean a reorientation away from Salafi-jihadist threats, or indeed the growing white supremacist and neo-Nazi menace. Instead, efforts against incels should form one part of a broader, more comprehensive strategy targeting homegrown, domestic terrorism — which, given that almost all ISIS attacks in Europe and North America have been committed by so-called "homegrown violent extremists" who were nationals of the countries they attacked, would effectively tackle the broader array of terrorist threats, keeping Americans safer. ${ }^{112}$

Despite persistent media and law enforcement attention, the extremist fringes of the incel community are flourishing, ideologically evolving, and continuing to threaten more such attacks. The violent manifestations of the ideology pose a new terrorism threat, which should not be dismissed or ignored by domestic law enforcement agencies.

\footnotetext{
${ }^{1}$ A notable exception is Stephane J. Baele, Lewys Brace, and Travis G. Coan, "From 'Incel' to 'Saint': Analyzing the violent worldview behind the 2018 Toronto attack," Terrorism and Political Violence (August 2019), DOI: 10.1080/09546553.2019.1638256.

${ }^{2}$ See Bruce Hoffman and Jacob Ware, "Incels: America's Newest Domestic Terrorism Threat," Lawfare, January 12, 2020, accessed at https://www.lawfareblog.com/incels-americas-newest-domestic-terrorismthreat.

${ }^{3}$ Jim Taylor, "The woman who founded the 'incel' movement," $B B C$, August 30, 2018, accessed at https://www.bbc.com/news/world-us-canada-45284455.

${ }^{4}$ Ashifa Kassam, "Woman behind 'incel' says angry men hijacked her word 'as a weapon of war," Guardian, April 25, 2018, accessed at https://www.theguardian.com/world/2018/apr/25/woman-whoinvented-incel-movement-interview-toronto-attack.
} 
${ }^{5}$ Sarah Manavis, "What is shitposting? And why does it matter that the BBC got it wrong?" New Statesman, November 8, 2019, accessed at https://www.newstatesman.com/politics/media/2019/11/whatis-shitposting-and-why-does-it-matter-bbc-brexitcast-laura-kuenssberg-got-it-wrong.

${ }^{6}$ Zack Beauchamp, "Our incel problem," Vox, April 23, 2019, accessed at https://www.vox.com/thehighlight/2019/4/16/18287446/incel-definition-reddit.

7 Tim Squirrell, "A definitive guide to Incels Part Three: the history of Incel," timsquirrell.com, June 4, 2018, accessed at: https://www.timsquirrell.com/blog/2018/6/4/a-definitive-guide-to-incels-part-three-thehistory-of-incel.

${ }^{8}$ Ibid; and, Beauchamp, "Our incel problem."

${ }^{9}$ Squirrell, "A definitive guide to Incels Part Three."

${ }^{10}$ Adi Robertson, "Reddit has broadened its anti-harassment rules and banned a major incel forum," The Verge, September 30, 2019, accessed at https://www.theverge.com/2019/9/30/20891920/reddit-

harassment-bullying-threats-new-policy-change-rules-subreddits.

${ }^{11}$ Squirrell, "A definitive guide to Incels Part Three."

${ }^{12}$ Beauchamp, "Our incel problem."

${ }^{13}$ Authors' observation.

${ }^{14}$ Manoel Horta Ribeiro, Jeremy Blackburn, Barry Bradlyn, Emiliano De Cristofaro, Gianluca Stringhini, Summer Long, Stephanie Greenberg, and Savvas Zannettou, "From Pick-Up Artists to Incels: A DataDriven Sketch of the Manosphere," arXiv, January 21, 2020, accessed at https://arxiv.org/abs/2001.07600.

${ }^{15}$ Ribeiro et al., "From Pick-Up Artists to Incels," 10.

${ }^{16}$ Baele et al., "From 'Incel' to 'Saint.",

17 "In other words, incels see themselves as that bottom 10 percent, and view their celibate status as a mathematical problem that's rigged against them." See Rebecca Jennings, "Incels Categorize Women by Personal Style and Attractiveness," Vox, April 28, 2018, accessed at https://www.vox.com/2018/4/28/17290256/incel-chad-stacy-becky.

18 "Elliot Rodger: How misogynist killer became 'incel hero,"” $B B C$, April 26, 2018, accessed at https://www.bbc.com/news/world-us-canada-43892189.

19 Although men are also often targeted. As one incel terrorist declared in his post-attack police interview, "we want to overthrow the Chads, which would force the Stacy's to be forced to reproduce with the incels." Alek Minassian, "Electronically Recorded Interview of Alek Minassian," Interview by Detective Robert Thomas, Toronto Police Sex Crimes Unit Polygraph Unit, April 23, 2018, accessed at http://www.seditionists.com/minassian1.pdf.

${ }^{20}$ Baele et al., "From 'Incel' to 'Saint,"” 9.

${ }^{21}$ Debbie Ging, "Alphas, Betas, and Incels: Theorizing the Masculinities of the Manosphere," Men and Masculinities 22, no. 4 (2019): 640, accessed at https://journals.sagepub.com/doi/10.1177/1097184X17706401.

22 Jack Bratich and Sarah Banet-Weiser, "From pick-up artists to incels: con (fidence) games, networked misogyny, and the failure of neoliberalism," International Journal of Communication 13 (2019): 5017, accessed at https://ijoc.org/index.php/ijoc/article/viewFile/13216/2822.

23 "Survey results - March 2020," Incels.co, March 24, 2020, accessed at https://incels.co/threads/surveyresults-march-2020.188748/. Survey results from October 2019 showed very similar responses. "Survey Results - Oct 2019," Incels.co, September 30, 2019, accessed at https://incels.co/threads/survey-resultsfor-october-2019.147774/.

${ }^{24}$ See, for example, Jeff Gruenewald, Steven Chermak, and Joshua Freilich, 'Distinguishing 'Loner' Attacks from Other Domestic Extremist Violence," Criminology \& Public Policy 12, no. 1 (2013): 65-91, accessed at https://onlinelibrary.wiley.com/doi/abs/10.1111/1745-9133.12008.

25 “Texas Domestic Terrorism Threat Assessment," Texas Department of Public Safety, January 2020, accessed at https://www.dps.texas.gov/director_staff/media_and_communications/2020/txTerrorThreatAssessment.p $\frac{\text { df. }}{26}$

${ }^{26}$ Baele et al., "From 'Incel' to 'Saint,"” 4, 17. 
${ }^{27}$ Elliot Rodger, My Twisted World: The Story of Elliot Rodger (2014), https:/www.documentcloud.org/documents/1173808-elliot-rodger-manifesto.html, 117.

${ }^{28}$ Beauchamp, "Our incel problem." Both Scott Beierle and Alek Minassian sought to "go ER."

${ }^{29}$ Rodger, in the video presaging his attack, described himself as "the supreme gentleman" who, despite this trait, was still rebuffed by women. See YouTube, "Retribution," TimesVideo, May 24, 2014, https://www.nytimes.com/video/us/100000002900707/youtube-video-retribution.html.

${ }^{30}$ Liam Casey, "Toronto van attack trial for Alek Minassian to begin March 2, delayed due to 'red tape,", Global News, December 16, 2019, accessed at https://globalnews.ca/news/6301982/alek-minassianmurder-trial/.

${ }^{31}$ David Mack, Amber Jamieson, and Julia Reinstein, "The Tallahassee Yoga Shooter Was A Far-Right Misogynist Who Railed Against Women And Minorities Online," BuzzFeed, November 5, 2018, accessed at https://www.buzzfeednews.com/article/davidmack/tallahassee-yoga-shooter-incel-far-right-misogynyvideo.

${ }^{32}$ Dominique Mosbergen, "Yoga Studio Shooting Hero Attacked Gunman With A Vacuum Cleaner And Broomstick," Huffington Post, November 05, 2018, accessed at https://www.huffpost.com/entry/joshuaquick-yoga-studio-shooting-hero_n_5be0040be4b01ffb1d03d434.

${ }^{33}$ David Tarrant and Jennifer Emily, "Family of Dallas courthouse shooter Brian Clyde believes he wanted to be killed," Dallas Morning News, June 19, 2019, accessed at https:/www.dallasnews.com/news/2019/06/20/family-of-dallas-courthouse-shooter-brian-clyde-believeshe-wanted-to-be-killed/.

${ }^{34}$ Rick Anderson, “'Here I am, 26, with no friends, no job, no girlfriend': Shooter's manifesto offers clues to 2015 Oregon college rampage," Los Angeles Times, September 23, 2017, accessed at https://www.latimes.com/nation/la-na-school-shootings-2017-story.html.

${ }^{35}$ Keegan Hankes and Alex Amend, "The Alt-Right is Killing People," Southern Poverty Law Center, February 5, 2018, accessed at https://www.splcenter.org/20180205/alt-right-killing-people.

${ }^{36}$ Harry Shukman, "Online comments reveal Florida gunman Nikolas Cruz idolized Santa Barbara shooter Elliot Rodger," Babe, February 15, 2018, accessed at https://babe.net/2018/02/15/nikolas-cruzelliot-rodger-35621.

${ }^{37}$ Rachel Kalish, and Michael Kimmel, "Suicide by mass murder: Masculinity, aggrieved entitlement, and rampage school shootings," Health Sociology Review 19, no. 4 (2010): 451-464, accessed at https://www.tandfonline.com/doi/abs/10.5172/hesr.2010.19.4.451.

${ }^{38}$ Saranac Hale Spencer, "Meme Inflates School Shooting Deaths," FactCheck.Org, May 14, 2019, accessed https://www.factcheck.org/2019/05/meme-inflates-school-shooting-deaths/.

39 Janice Johnston, "Frustration over involuntary celibacy led to killing, former security guard claims," $C B C$, August 29, 2018, accessed at https://www.cbc.ca/news/canada/edmonton/edmonton-involuntarycelibacy-sheldon-bentley-manslaughter-jail-1.4803943.

${ }^{40}$ Reis Thebault, "Man who threw a boy off a mall balcony after 'looking for someone to kill' gets 19year sentence," Washington Post, June 3, 2019, accessed at https:/www.washingtonpost.com/nation/2019/06/04/man-who-threw-boy-off-mall-balcony-afterlooking-someone-kill-gets-year-sentence/.

${ }^{41}$ State of Minnesota, County of Hennepin, District Court, $4{ }^{\text {th }}$ Judicial District, State of Minnesota vs Emmanuel Deshawn Aranda, accessed at https:/www.hennepinattorney.org//media/Attorney/NEWS/2019/Aranda-emmanuelcplt.pdf?la=en\&hash=EE6811706337FD586E4EE26EF16542B53F42CCC7.

${ }^{42}$ Harold Carmichael, "Sudbury 'incel' attacker told cops: 'I was going to kill a child,", Toronto Sun, January 14, 2020, accessed at https://torontosun.com/news/provincial/sudbury-incel-attacker-told-cops-iwas-going-to-kill-a-child.

${ }^{43}$ See, for example, Rachel Pain, "Everyday terrorism: Connecting domestic violence and global terrorism," Progress in Human Geography 38, no. 4 (2014): 531-550, accessed at https://journals.sagepub.com/doi/abs/10.1177/0309132513512231. 
44 Tracey Lindeman, “'Hate is infectious': how the 1989 mass shooting of 14 women echoes today," Guardian, December 4, 2019, accessed at https://www.theguardian.com/world/2019/dec/04/massshooting-1989-montreal-14-women-killed.

${ }^{45}$ Talal Ansari and Ariane Lange, "Nearly 10 Years Apart, Attacks On Women Have Eerie Similarities," BuzzFeed, November 5, 2018, accessed at https://www.buzzfeednews.com/article/talalansari/la-fitnesstallahassee-yoga-shooter-incels-misogyny.

${ }^{46}$ Anderson, "'Here I am, 26, with no friends, no job, no girlfriend."”

${ }^{47}$ The "alt-right" can be defined as "a range of people on the extreme right who reject mainstream conservatism in favor of forms of conservatism that embrace implicit or explicit racism or white supremacy." See "Alt Right: A Primer on the New White Supremacy," Anti-Defamation League, accessed at https://www.adl.org/resources/backgrounders/alt-right-a-primer-on-the-new-white-supremacy.

${ }^{48}$ Justin Gilmore, "Incels: The New Politics of Indifference," Center for Analysis of the Radical Right, November 11, 2019, accessed at https://www.radicalrightanalysis.com/2019/11/11/incels-the-newpolitics-of-indifference/.

${ }^{49}$ Anti-Defamation League, "When Women are the Enemy: The Intersection of Misogyny and White Supremacy," 2018, accessed at https://www.adl.org/resources/reports/when-women-are-the-enemy-theintersection-of-misogyny-and-white-supremacy.

${ }^{50}$ Rodger, My Twisted World, 84.

${ }^{51}$ See, for example, Faima Bakar, "In the midst of racism and violence, why is the incel community still so appealing?" Metro, August 14, 2019, accessed at https://metro.co.uk/2019/08/14/in-the-midst-ofracism-and-violence-why-is-the-incel-community-still-so-appealing-10563245/.

52 The "Zionist Occupied Government" conspiracy theory is a central tenet of neo-Nazi and white supremacist ideology. See Beauchamp, "Our incel problem."

${ }^{53}$ Scott Hendrix, "He Always Hated Women. Then He Decided To Kill Them." Washington Post, June 7, 2019, accessed at https://www.msn.com/en-us/news/crime/he-always-hated-women-then-he-decided-tokill-them/ar-AACxF5w.

${ }^{54}$ Chris Baynes, "Florida shooting suspect Nikolas Cruz 'etched swastikas into ammunition magazines used in massacre," Independent, February 28, 2018, accessed at https://www.independent.co.uk/news/world/americas/florida-shooting-nikolas-cruz-swastikasammunition-magazines-parkland-massacre-a8232916.html.

55 "New Mexico School Shooter Also Fixated on Violence Against Jews," Anti-Defamation League, December 18, 2017, accessed at https://www.adl.org/blog/new-mexico-school-shooter-also-fixated-onviolence-against-jews.

${ }^{56}$ See, for example, "The Anti-Defamation League published 'A Guide to Online Pills,"” Incels.co, November 7, 2019, accessed February 25, 2020, https://incels.co/threads/the-anti-defamation-leaguepublished-a-guide-to-online-pills.156234/.

${ }^{57}$ Anti-Defamation League, "When Women are the Enemy."

${ }^{58}$ Minassian, "Electronically Recorded Interview of Alek Minassian."

${ }^{59}$ Aja Romano, "How the alt-right's sexism lures men into white supremacy," Vox, April 26, 2018, accessed at https://www.vox.com/culture/2016/12/14/13576192/alt-right-sexism-recruitment.

${ }^{60}$ Helen Lewis, "To Learn About the Far-Right, Start With the "Manosphere,"” The Atlantic, August 7 , 2019, accessed at https:/www.theatlantic.com/international/archive/2019/08/anti-feminism-gateway-farright $/ 595642 /$.

${ }^{61}$ Martin Bernstein, "Das Netzwerk der Todesschützen," Süddeutsche Zeitung, May 15, 2018, accessed at https://www.sueddeutsche.de/muenchen/oez-attentaeter-amoklaeufer-kontakt-1.3979444.

${ }^{62}$ Øyvind Strømmen, "Inn i mørkret," NRK, August 13, 2019, accessed at https://www.nrk.no/ytring/inni-morkret-1.14658755.

63 "Halle-Attentäter glaubt an jüdische Weltverschwörung," Der Spiegel, October 25, 2019, accessed at https:/www.spiegel.de/panorama/justiz/halle-attentaeter-stephan-balliet-glaubt-an-juedischeweltverschwoerung-a-1293330.html. 
${ }^{64}$ Daniel Koehler, "The Halle, Germany, Synagogue Attack and the Evolution of the Far-Right Terror Threat," CTC Sentinel, 12, no. 11 (December 2019), p. 16, accessed at https://ctc.usma.edu/hallegermany-synagogue-attack-evolution-far-right-terror-threat/.

${ }^{65}$ Tim Hume, "Not a Classical Neo-Nazi': What We Know About the German Hookah Bar Terrorist," Vice, February 20, 2020, accessed at https://www.vice.com/en_us/article/n7jdak/race-hate-mind-controland-incel-ideology-what-we-know-about-the-german-hookah-bar-shooter.

${ }^{66}$ For more on the links between Western militaries and the far-right, see Daniel Koehler, "A Threat from Within? Exploring the Link between the Extreme Right and the Military," International Centre for Counter-Terrorism - The Hague, September 2019, accessed at https://icct.nl/wpcontent/uploads/2019/09/ICCT-Koehler-A-Threat-from-Within-Exploring-the-Link-between-theExtreme-Right-and-the-Military.pdf.

${ }^{67}$ Minassian told police he "was interesting in learning how to use weapons, specifically large guns, such as assault rifles." Minassian, "Electronically Recorded Interview of Alek Minassian." See also "Toronto van attack: What we know about suspect Alek Minassian," Global News, April 26, 2018, accessed at https://globalnews.ca/news/4162755/toronto-van-attack-alek-minassian/.

${ }^{68}$ Hendrix, "He Always Hated Women."

${ }^{69}$ Jack Healy and Ian Lovett, "Oregon Killer Described as Man of Few Words, Except on Topic of Guns," New York Times, October 2, 2015, accessed at https://www.nytimes.com/2015/10/03/us/chrisharper-mercer-umpqua-community-college-shooting.html.

${ }^{70}$ Eliott C. McLaughlin and Madison Park, "Social media paints picture of racist 'professional school shooter,"' CNN, February 16, 2018, accessed at https://www.cnn.com/2018/02/14/us/nikolas-cruz-floridashooting-suspect/index.html.

${ }^{71}$ Jake Bleiberg, "FBI got tip about Dallas courthouse shooter in 2016 while he was in the Army," Army Times, June 20, 2019, accessed at https://www.armytimes.com/news/your-army/2019/06/20/fbi-got-tipabout-dallas-courthouse-shooter-in-2016/.

${ }^{72}$ Graeme Wood, "ISIS Tactics Have Spread to Other Violent Actors," The Atlantic, April 24, 2018, accessed at https://www.theatlantic.com/international/archive/2018/04/toronto-van-incel/558836/.

${ }^{73}$ Minassian, "Electronically Recorded Interview of Alek Minassian."

74 “Happy St. Yogacel day bro's.” Incels.co, November 3, 2019, accessed February 25, 2020, https://incels.co/threads/happy-st-yogacel-day-bros.155231/.

${ }^{75}$ Minassian, "Electronically Recorded Interview of Alek Minassian."

${ }^{76}$ Bruce Hoffman, "How Serious Is White Nationalist Terrorism?" Council on Foreign Relations, March 29, 2019, accessed at https://www.cfr.org/in-brief/how-serious-white-nationalist-terrorism.

${ }^{77}$ For more, see Jerrold Post, Cody McGinnis, and Kristen Moody, "The Changing Face of Terrorism in the 21st Century: The Communications Revolution and the Virtual Community of Hatred," Behavioral Sciences \& the Law 32, no. 3 (2014): 306-334, accessed at https://onlinelibrary.wiley.com/doi/abs/10.1002/bsl.2123.

${ }^{78}$ Rachel Janik, "I laugh at the death of normies': How incels are celebrating the Toronto mass killing," Southern Poverty Law Center, April 24, 2018, accessed at https://www.splcenter.org/hatewatch/2018/04/24/i-laugh-death-normies-how-incels-are-celebratingtoronto-mass-killing.

${ }^{79}$ Minassian, "Electronically Recorded Interview of Alek Minassian."

${ }^{80}$ Nasra Hassan, "An Arsenal of Believers," New Yorker, November 11, 2001, accessed at https://www.newyorker.com/magazine/2001/11/19/an-arsenal-of-believers.

${ }^{81}$ See, for example, Nico Hines, "Domineering Dads and Sexual Frustration Driving Kids in the West to ISIS," Daily Beast, April 14, 2017, accessed at https://www.thedailybeast.com/domineering-dads-andsexual-frustration-driving-kids-in-the-west-to-isis.

${ }^{82}$ Simon Cottee, "Sex and Shame: What Incels and Jihadists Have in Common," New York Times, April 30, 2018, accessed at https://www.nytimes.com/2018/04/30/opinion/sex-shame-incels-jihadistsminassian.html. 
${ }^{83}$ Mark Juergensmeyer, Terror in the Mind of God: The Global Rise of Religious Violence 4th ed. (Oakland: University of California Press, 2017), 241.

${ }^{84}$ Wood, "ISIS Tactics Have Spread to Other Violent Actors."

${ }^{85}$ Bruce Hoffman, "The Logic of Suicide Terrorism," The Atlantic, June 2003, accessed at https://www.theatlantic.com/magazine/archive/2003/06/the-logic-of-suicide-terrorism/302739/.

${ }^{86}$ Dell Cameron, "U.S. Military Issues Warning to Troops About Incel Violence at Joker Screenings [Updated]," Gizmodo, September 24, 2019, accessed at https://io9.gizmodo.com/u-s-military-issueswarning-to-troops-about-incel-viol-1838412331.

87 “Texas Domestic Terrorism Threat Assessment," Texas Department of Public Safety, January 2020, available at https://www.dps.texas.gov/director_staff/media and_communications/2020/txTerrorThreatAssessment.p df.

${ }^{88}$ See, for example, Daniel Byman, "Can Lone Wolves Be Stopped?" Lawfare, March 15, 2017, accessed at https://www.lawfareblog.com/can-lone-wolves-be-stopped.

${ }^{89}$ Minassian, "Electronically Recorded Interview of Alek Minassian."

90 "I'd rather join a suicult than go ER," Incels.co, November 21, 2019, accessed February 25, 2020, https:/incels.co/threads/id-rather-join-a-suicult-than-go-er.159183/.

${ }^{91}$ Tanya Basu, "The "manosphere" is getting more toxic as angry men join the incels," MIT Technology Review, February 7, 2020, accessed at https://www.technologyreview.com/s/615155/the-manosphere-isgetting-more-toxic-as-angry-men-join-the-incels/.

${ }_{92}$ Baele et al., "From 'Incel' to 'Saint,"” 18.

${ }^{93}$ Taylor, "The woman who founded the 'incel' movement."

94 "Violent misogyny, mass murder and suicide: it's time to save incels from themselves," Moonshot CVE, September 10, 2019, http://moonshotcve.com/save-incels-from-themselves/.

${ }^{95}$ Secretary of State for Digital, Culture, Media \& Sport and the Secretary of State for the Home Department, Online Harms White Paper: Presented to Parliament, CP 57, April 2019, accessed at: https:/assets.publishing.service.gov.uk/government/uploads/system/uploads/attachment_data/file/793360 /Online_Harms_White_Paper.pdf.

96 "The Call," Christchurch Call to Eliminate Terrorist and Violent Extremist Content Online," https://www.christchurchcall.com/call.html.

${ }^{97}$ See, for example, Daniel Byman, "An Intelligence Reserve Corps to Counter Terrorist Use of the Internet," Lawfare, August 10, 2018, accessed at https://www.lawfareblog.com/intelligence-reservecorps-counter-terrorist-use-internet; Neil MacFarquhar, "White Extremism Faces a Subversive Foe Online: Google Ads," New York Times, December 31, 2019, accessed at https://www.nytimes.com/2019/12/30/us/white-supremacy-moonshot-google-ads.html; Audrey Alexander, "A Plan for Preventing and Countering Terrorist and Violent Extremist Exploitation of Information and Communications Technology in America," GW Program on Extremism, September 2019, accessed at https:/extremism.gwu.edu/sites/g/files/zaxdzs2191/f/A\%20Plan\%20for\%20Preventing\%20and\%20Count ering\%20Terrorist\%20and\%20Violent\%20Extremist.pdf; and "Countering Online Radicalization in America," Bipartisan Policy Center, December 2012, accessed at https://bipartisanpolicy.org/report/countering-online-radicalization-america-0/.

${ }^{98}$ Baele et al., "From 'Incel' to 'Saint,", 20.

${ }^{99}$ For more, see Mark S. Hamm and Ramon Spaaij, The Age of Lone Wolf Terrorism (New York: Columbia University Press, 2017).

${ }^{100}$ See, for example, Laura Sjoberg, "Gender, structure, and war: What Waltz couldn't see," International Theory 4, no. 1 (2012): 1-38, accessed at https://www.cambridge.org/core/journals/internationaltheory/article/gender-structure-and-war-what-waltz-couldntsee/E8F3366CFB2F50D48D0DD8E4680B3AE6; Cynthia Cockburn, "Gender Relations as Causal in Militarization and War," International Feminist Journal of Politics 12, no. 2 (2010): 139-157, accessed at 
https://www.tandfonline.com/doi/abs/10.1080/14616741003665169; Kalish and Kimmel, "Suicide by mass murder," 459.

${ }^{101}$ Laura Sjoberg, Gendering Global Conflict: Toward a Feminist Theory of War (New York: Columbia University Press, 2013), 14.

${ }^{102}$ Michael Kimmel, Angry White Men: American Masculinity at the End of an Era (New York: PublicAffairs, 2017).

${ }^{103}$ See, for example, Cynthia Miller-Idriss and Hilary Pilkington, Gender and the Radical and Extreme Right: Mechanisms of Transmission and the Role of Educational Interventions (Abingdon: Routledge, 2019); and Ashley A. Mattheis and Charlie Winter, “The Greatness of Her Position': Comparing Identitarian and Jihadi Discourses on Women," International Centre for the Study of Radicalisation, 2019, accessed at https://icsr.info/2019/05/15/the-greatness-of-her-position-comparing-identitarian-andjihadi-discourses-on-women/.

${ }^{104}$ Ging, "Alphas, Betas, and Incels: Theorizing the Masculinities of the Manosphere."

${ }^{105}$ Maria N. Scaptura and Kaitlin M. Boyle, "Masculinity Threat, 'Incel' Traits, and Violent Fantasies Among Heterosexual Men in the United States," Feminist Criminology (2019), accessed at https://journals.sagepub.com/doi/abs/10.1177/1557085119896415.

${ }^{106}$ Alice E. Marwick and Robyn Caplan, "Drinking male tears: language, the manosphere, and networked harassment," Feminist Media Studies 18, no. 4 (2018): 543-559, accessed at https://www.tandfonline.com/doi/full/10.1080/14680777.2018.1450568.

${ }^{107}$ See, for example, Alex DiBranco, "Male Supremacist Terrorism as a Rising Threat," International Centre for Counter-Terrorism - The Hague, February 10, 2020, accessed at https://icct.nl/publication/male-supremacist-terrorism-as-a-rising-threat/.

${ }^{108}$ Kate Manne, Down Girl: The Logic of Misogyny (New York: Oxford University Press, 2018).

${ }^{109}$ Romano "What a woman-led incel support group can teach us about men and mental health."

${ }^{110}$ Kalish and Kimmel, "Suicide by mass murder," 459.

${ }^{111}$ Zack Beauchamp, "Incel, the misogynist ideology that inspired the deadly Toronto attack, explained," Vox, April 25, 2018, accessed at https://www.vox.com/world/2018/4/25/17277496/incel-toronto-attackalek-minassian.

${ }^{112}$ For more on homegrown Salafi-jihadist terrorism, see Peter Bergen, United States of Jihad: Who Are America's Homegrown Terrorists, and How Do We Stop Them? (New York: Broadway Books, 2017). 